\title{
CLAVES PARA VALORAR EL MARKETING MÓVIL
}

Laura Melendo Rodríguez-Carmona1: Universidad Camilo José Cela. España lmelendo@ucjc.edu

\section{RESUMEN}

El teléfono móvil es, en la actualidad y con los recursos materiales existentes, un medio que ha conseguido poner fin a las limitaciones de los medios de comunicación anteriores. Este medio portátil reúne las pretensiones que el ser humano ha buscado desde sus orígenes en un medio de comunicación. Además, en el uso de este medio para realizar acciones de marketing y comunicación se potencian sus características como medio de comunicación y lo convierten en una herramienta idónea a incorporar en las estrategias de marketing. En el presente artículo se exponen algunas de las razones por las que se realizan las dos anteriores afirmaciones.

PALABRAS CLAVE: Medios de comunicación - Teléfono - Marketing Móvil Publicidad

\footnotetext{
${ }^{1}$ Autor correspondiente Laura Melendo Rodríguez-Carmona profesora de la Universidad Camilo José Cela. España Correo: 1melendo@ucjc.edu
} 


\title{
VALUING MOBILE MARKETING
}

\begin{abstract}
Mobile phones have enabled us to put an end to the limitations that previous mass media introduced in the past. This portable means of communication encompasses all the characteristics that human beings have been looking for since the origins of communication. Therefore the mobile phone is an ideal tool to develop marketing and communications strategies.
\end{abstract}

KEY WORDS: Mass Media - Telephone - Mobile Marketing - Advertising

\section{INTRODUCCIÓN}

El objetivo de este artículo es "describir una pequeña parte del mundo donde también suceden cosas, como en cualquier otro sitio" (Smoke, 1995). De esta misma manera explicaba el guionista y escritor Paul Auster la obra de su vida en la película Smoke. El protagonista de esta película, Auggie Wren, interpretado por el actor Harvey Keitel, realizaba cada mañana a la misma hora una fotografía a la fachada de su estanco.

Con este proyecto estaba realizando una crónica de su rincón del mundo. Había realizado más de 4.000 fotografías que tenía ordenadas en varios álbumes. Decía que había que verlas despacio, sin prisa, ya que todas eran iguales pero cada una distinta a la otra. En unas aparecían personas en camiseta y pantalón corto, en otras con abrigo y botas de agua; en otras había días nublados y en otras días con sol; en algunas luz de verano y en otras luz de otoño; algunas eran días laborables y otras festivos.

Eso es lo que se ha pretendido con este artículo, describir los pros de la incorporación del marketing móvil en España en un determinado periodo, logrando de esa manera, al igual que hiciera Auggie Wren, describir una pequeña parte del mundo donde también suceden cosas. 


\section{METODOLOGÍA}

El estudio emplea como técnica científica el método análitico-sintético, mediante el cual se el teléfono como un objeto, en los principales elementos que lo integran para analizar, valorar y conocer sus particularidades, y simultaneámente a través de la síntesis, se analiza su interrelación con las acciones de marketing y comunicación.

\section{ANÁLISIS Y DISCUSIÓN}

\subsection{Punto de partida}

Autores como Haig (Haig, 2002), Dickinger, Haghiarian, Murphy y Scharl (Dickinger, Haghiarian, Murphy \& Scharl, 2004), Sánchez Guzmán (Sánchez Guzmán, 2004), Hermoso de Mendoza Blanco (Hermoso de Mendoza Blanco, 2004), Kotler y Armstrong (Kotler \& Armstrong, 2006), Michale y Salter (Michale \& Salter, 2006), Martín de Bernardo González (Martín de Bernardo González, 2007), han presentado en sus obras las cualidades del teléfono móvil como herramienta de marketing, abordando la definición de marketing móvil, describiendo sus características y ventajas diferenciadoras, así como las diversas modalidades actualmente empleadas. También han descrito los principales usos dentro de la estrategia general de marketing y sus diferentes tipologías.

Si bien los autores anteriormente citados describen cómo es el marketing móvil, también es oportuno conocer el uso que los españoles hacen de este nuevo medio de comunicación. Su conocimiento y análisis será indispensable para terminar de ilustrar porqué el teléfono móvil ha de ser considerado un medio más en los planes de comunicación, publicidad y medios. Este análisis del empleo del teléfono móvil ayudaría por tanto a verificar su idoneidad en las acciones de marketing o de comunicación que el anunciante pueda desarrollar dentro de su estrategia.

\subsection{El proceso de comunicación a través de un teléfono móvil}

Como se comentaba al principio de este texto, el teléfono móvil es, en la actualidad y con los recursos materiales existentes, un medio que acaba con las limitaciones de los medios de comunicación anteriores y que reúne las exigencias que el ser humano ha buscado desde sus orígenes en un medio de comunicación.

La evolución de la ciencia y de las tecnologías de la información y telecomunicación ha generado la introducción de los medios de comunicación en el proceso de comunicación humana, proceso que ha culminado con la telefonía móvil. Esto ha supuesto que se generen ciertas modificaciones tanto en la tipología de la comunicación humana como en la descripción del propio proceso. Gracias a estos medios, la tipología de comunicación humana evoluciona distinguiéndose entre 
En una comunicación personal el emisor se relaciona directamente con el receptor. La comunicación tiene un carácter oral y se realiza cara a cara. Esta comunicación está condicionada por las habilidades comunicativas del emisor y del receptor ya que se emplea el discurso y el lenguaje corporal.

Es acertado, para el proceso de comunicación personal, el concepto de comunicación que describía Aristóteles (González, 2005). Con tan sólo cinco palabras: quién dice qué a quién afirmaba que el proceso de comunicación sólo dependía de tres variables: el orador, el discurso y el auditorio (Berlo, 2004).

En la comunicación de masas se incorporan elementos que tornan el modelo de Aristóteles insuficiente. Otros autores (Lucas Martín, García Galera \& Ruiz San Román, 1999), por ejemplo, subrayan la ampliación cuantitativa de este proceso al crecer el número de mensajes, emisores y receptores involucrados en el proceso comunicativo mediado. Y advierten que la definición de Aristóteles no contempla ni el canal, ni las posibles consecuencias que pueda tener esta comunicación. El modelo de Lasswell se ajustaría mejor a este tipo de comunicación quien define el proceso de la siguiente manera: quién, dice qué, a quién, en qué canal, a quién y con qué efectos.

En esta comunicación los medios se interponen entre emisor y receptor siendo la relación entre el emisor y el medio y entre el medio y el receptor. De manera que el rendimiento del proceso de comunicación empieza a depender no de la habilidad comunicativa del hombre (discurso oral), sino de la habilidad de interacción de éste con el medio y de la capacidad técnica comunicativa del medio, y así los medios se consideran extensiones sensoriales del individuo (McLuhan, 1973).

Desde su origen, el animal se ha comunicado con sus semejantes mediante señales, empleando los diferentes mecanismos biológicos de los que estaba dotado. Gracias a esta comunicación, marca su territorio, se defiende, se reproduce... pero siempre está limitado a sus capacidades biológicas.

El ser humano, dotado de ciertas ventajas físicas e intelectuales, pronto se diferenció por el uso del lenguaje. Pudo razonar, interactuar y ser superior al resto de animales. Pero necesitaba más, necesitaba poder almacenar de algún modo la información que transmitía de manera oral. Así surgieron los signos y la escritura, y con ellos hacía perenne y transportable la información. Con el fin de mejorar estos aspectos y el almacenamiento de la información, inventó una superficie ligera y fácil de transportar: el papel. Con la imprenta introducía una máquina en el proceso de comunicación. Con ella abarató los costes y ganó rapidez en el proceso de producción de los libros. Pero seguía sin poder comunicarse a distancia. 
La invención del telégrafo acababa con esa limitación, permitiendo la comunicación a distancia de manera casi instantánea a través de los cables de la electricidad. Pero el telégrafo era un aparato difícil de manejar, supeditado a la codificación y posterior traducción por un experto en código Morse, no era accesible a toda la población. Tras la invención del telégrafo, se sucedería la de muchos más aparatos que acercarían al humano al proceso de comunicación actual.

El teléfono acercaba a toda la población la comunicación a distancia mediante la transmisión de la palabra. La fotografía, por su parte, incorporaba la imagen y el cine, la imagen en movimiento.

La radio difundía mensajes hablados, música y sonidos por todo el mundo sin la dependencia de los cables, dando lugar al primer medio de comunicación de masas que permitía transmitir mensajes a una gran cantidad de receptores.

La imagen se logró transmitir con la televisión que, además de ser un medio de comunicación de masas, era ubicuo, inmediato y portátil.

Las nuevas tecnologías ampliaron la capacidad de almacenamiento y tratamiento de la información con las computadoras, conectaron a los usuarios mediante internet permitiéndoles comunicarse entre sí y daban acceso, mediante los videojuegos, a un mundo virtual donde poder interactuar. Pero el último en llegar, el teléfono móvil, acababa con las limitaciones de todos los medios de comunicación anteriores, reuniendo las ventajas que cada uno de ellos había aportado al proceso de comunicación.

Llegados a este punto, se puede proceder a establecer el decálogo que confirmaría la primera hipótesis planteada en este texto. Dicho decálogo destaca las aportaciones de la telefonía móvil al proceso de comunicación:

La telefonía móvil permite una comunicación ubicua por su capacidad de estar presente en todas partes, ya que es un medio portátil. La comunicación a través de este medio es instantánea y casi pentasensorial ya que transmite la palabra, el sonido, música, imagen fija y en movimiento (y en un futuro funcionará incluso como una nariz y lengua electrónica (Fernández Vicente, 2008).

También es un medio de comunicación de masas accesible para todos los usuarios (teniendo en cuenta la brecha digital) a los que les permite interactuar en mundos virtuales. Además la interactividad y la posibilidad del tratamiento de la información incorporan al teléfono móvil la capacidad de actuar como canal de transmisión y almacenamiento de la información. 


\subsection{Valorando el marketing móvil}

Este medio es una herramienta idónea a incorporar en las estrategias de marketing debido a que en el marketing móvil se potencian las cualidades del teléfono móvil como medio de comunicación.

Se llega a esta afirmación al comprobar las características y ventajas diferenciadoras que tiene el marketing móvil, los usos y oportunidades de incorporación a la estrategia general de marketing y las tipologías existentes.

Las principales características y ventajas del marketing móvil son: que es personal, es ubicuo, es interactivo, permite una comunicación inmediata y sincrónica, es integrable en la estrategia global de comunicación, permite la viralidad y no es intrusivo. A continuación se presentan las principales acotaciones de dichas características.

El marketing móvil es personal ya que cada usuario tiene asociado un número de línea. Esto ha generado que hablar de un individuo, sea hablar de un número de teléfono, de una línea e incluso de un terminal. Por eso es un medio que asegura el contacto directo con su usuario. Porque llamar a un número móvil es llamar a una persona, no a un lugar. A diferencia del teléfono fijo, como tradicionalmente estaba concebido, en el que la línea está asociada a un lugar físico. Por ejemplo: llamar a la oficina o llamar a una casa particular. Y en ese lugar cualquiera podía contestar. Por ello las acciones de marketing realizadas a través de un terminal alcanzan un alto grado de personalización y segmentación. Las acciones se pueden individualizar, tanto el mensaje como el destinatario del mismo. Así, las empresas pueden dirigir mensajes distintos y ofrecer productos o servicios diferentes a cada cliente, adecuados a las necesidades y circunstancias del cliente.

A diferencia del teléfono fijo, como tradicionalmente estaba concebido, en el que la línea está asociada a un lugar físico, el marketing móvil es ubicuo. Así, imaginaba Ferraris (Ferraris, 2008), si alguien llamase a un teléfono fijo y preguntase: ¿dónde estás? La respuesta, atónita e imprevisible, sería: ¿dónde quieres que esté? Estoy aquí, donde me llamas. En cambio, con el móvil es del todo distinto: lo primero que preguntamos es ¿Dónde estás? Porque ahora el interlocutor puede estar en cualquier sitio. El teléfono móvil ha cambiado la tradicional relación con el espacio: por remoto o periférico que sea el lugar donde nos encontremos siempre estamos localizables, en medio del mundo.

Así el marketing móvil logra la ubicuidad en sus acciones cuando, más allá de localizar al individuo geográficamente, se logra localizar al individuo como tal, en función de sus gustos, preferencias, demandas o características. 
Aunque habría que mencionar que, gracias a los sistemas de localización integrados en los móviles, el marketing móvil también logra ubicar a sus públicos, de manera que sean objetivo de sus campañas aquellos que están en un determinado lugar en un determinado momento.

El marketing móvil es interactivo, ya que permite el diálogo entre emisor y receptor. La bidireccionalidad de este medio permite que haya diálogo entre ambos, mejorando el intercambio de información y su relación. Esto es muy ventajoso para los dos. El anunciante, al tener acceso a los gustos, preferencias o necesidades de su público objetivo y el público, tiene una vía directa de contacto con el cliente, que le puede servir, entre otros, como servicio postventa, información al consumidor, a ofertas o promociones.

También es un canal inmediato que permite llegar al público de manera instantánea y en cualquier momento gracias a la gran rapidez de envío y de respuesta que ofrece. La inmediatez en las campañas de marketing otorga la ventaja de poder conocer, por ejemplo, el funcionamiento de las acciones, su recibimiento, los horarios de preferencia.

El marketing móvil es sincrónico al ser la recepción de los envíos inmediata, y también su lectura. Por eso la ventaja anterior, referida a la inmediatez en el envío de los mensajes, se mejora por el carácter sincrónico en la lectura de los mensajes. Al llevar el móvil siempre consigo, los usuarios pueden recibir el mensaje y leerlo al instante.

De esta manera el marketing móvil logra un tipo de acción que respondería al mundo que describe Virilio: el aquí no existe, todo es ahora. Se acelera el tiempo real al permitir la telefonía el diálogo instantáneo. Y esta aceleración hace que la distancia entre el anunciante y sus públicos desaparezca (Virilio, 1999).

Además, el marketing móvil es integrable en la estrategia global de marketing. Este medio se puede integrar de diferentes maneras en la estrategia global de marketing y comunicación del anunciante. Puede ser de manera complementaria, otorgándole un papel secundario y sirviéndose de él para generar tráfico hacia otros medios o bien como medio principal de la acción. Otros medios también se apoyan en él como segunda vía de contacto con el target.

El marketing móvil permite la viralidad: en la telefonía móvil sucede lo mismo que en internet: los usuarios se reenvían todo aquello que les resulta de interés. Esto favorece la expansión de los mensajes y por ende de las acciones de comunicación generadas por el anunciante. Esta potencialidad del teléfono móvil como generador de reenvío de mensajes está amparada por cifras muy atractivas: el 69\% de la gente reenvía el contenido que le gusta a ente 2 y 6 amigos, y el $64 \%$ de la gente probará 
Si es con permiso, el marketing móvil no es intrusivo. Puede llegar a ser muy personal, y contactar directamente con un individuo pero éste ha debido de autorizar previamente al emisor para que contacte con él. Los aspectos positivos señalados anteriormente como la personalización de la comunicación pueden volverse en contra de los anunciantes cuando no respetan la legislación. Cumpliendo la normativa se potenciará esa ventaja y se logrará la mejor respuesta por parte del destinatario, ya que, nos estamos metiendo en una parcela muy privada en la vida del consumidor, puesto que llegamos a él cuándo queremos y cómo queremos, con mensajes que pueden generar reacciones muy distintas a las que se obtienen con otros medios (Hermoso de Mendoza, 2007).

El diseño de la estrategia general de marketing ha de contar con un conjunto de instrumentos de marketing tácticos y controlable (producto, precio, distribución y comunicación) que la empresa combinará para generar las respuestas deseadas en el mercado objetivo. Entre estos instrumentos se pueden encontrar, por lo tanto, los anteriormente enumerados. Ya que, de acuerdo con Chema Ramos, director de marketing de MoviDream "los usos que se le den al móvil podrán ser tan variados como la estrategias de marketing que seamos capaces de idear" (Román, González-Mesones \& Marinas, 2005).

Por eso se abordan los usos del marketing móvil como estrategia subordinada a la estrategia general de marketing y se concretan mediante ejemplos los más empleados: uso del marketing móvil en acciones promocionales, para realizar publicidad, advergaming, campañas de fidelización, imagen de marca, M-Commerce y análisis de mercado. A continuación se resumen las principales conclusiones del uso de cada uno de ellos:

Uso del marketing móvil en acciones promocionales. El éxito del teléfono móvil en las promociones le viene dado por las propias características del medio. La instantaneidad del medio, la personalización del mensaje, la cercanía al cliente en el momento de compra, y la posibilidad de unir en un mismo canal el medio, el mensaje y el canal de respuesta logran que las promociones a través de este medio se puedan hacer desde cualquier lugar, en cualquier momento y de forma inmediata (aunque se deba cuidar su aplicación a cada sector y tipo de consumidor ya que cada uno tiene un grado de idoneidad diferente).

Uso del marketing móvil para realizar publicidad. La publicidad móvil es una forma de publicidad que emplea el teléfono móvil para comunicarse con su consumidor o target. Y el teléfono móvil es un soporte publicitario que cuenta con todos los requisitos para ser totalmente idóneo: la audiencia (objeto de estudio y análisis en el marco práctico), su capacidad de segmentación, la interactividad, la posibilidad de medición en tiempo real, así como la variedad de formatos que incluye. 
Uso del marketing móvil para desarrollar advergaming. La principal ventaja que este formato ofrece a una acción de marketing, es poder huir de la saturación de los anuncios en los medios convencionales aunque tiene muchas más características del medio que lo hacen interesante para los anunciantes: la alta penetración, que no se presenta de manera intrusiva, la perdurabilidad del juego y la alta frecuencia de uso semanal, entre otros.

Uso del marketing móvil en campañas de fidelización. El éxito de este tipo de actuaciones viene respaldado fundamentalmente, por tres características del medio: las capacidades del terminal como herramienta comercial y su poder para enviar todo tipo de contenidos informativos promocionales que ayuden a incrementar los niveles de fidelización del cliente, por sus niveles de eficacia están muy por encima de los de cualquier otro tipo de medio de comunicación, y por la rentabilidad que se obtiene de la inversión, que está en torno al veinte por ciento (Escuderos, 2006).

Uso del marketing móvil para hacer imagen de marca. Se presenta como el objetivo más difícil para una campaña de marketing que emplee este medio, y generar imagen de marca a través del móvil necesita el apoyo de otras acciones.

Uso del marketing móvil para realizar M-Commerce. Usar el móvil como monedero para pagar compras. Esta es la clave de unas previsiones que indican que el crecimiento del comercio electrónico a través del móvil será tres veces superior al de la fase inicial de internet. Esto es debido principalmente a dos razones: que el número de usuarios de telefonía móvil supera ya al de internautas y a que las previsiones de que el acceso a internet a través del móvil crecerá en los próximos años de manera muy significativa.

Uso del marketing móvil para llevar a cabo análisis de mercado. Si ya todo se quiere hacer por el móvil, ¿cómo no pasar a aplicar metodologías de investigación mediante este tipo de telefonía? Respecto a las ventajas de esta nueva amanera de recopilar información, destaca que: "la investigación mediante el móvil nos permite recibir feedback en cualquier momento, en cualquier lugar y cuando lo desee el encuestado. Además les resulta rentable a nuestros clientes" (marketingnews.es, 2009).

Mediante el análisis y ejemplificación de estos usos aplicados a acciones mediante el empleo del teléfono móvil se vuelve a contrastar la idoneidad de las acciones de marketing para cualquier necesidad de comunicación y marketing que el anunciante tenga.

\section{CONCLUSIONES}

Este trabajo sirve para, en primer lugar, conocer mejor la telefonía móvil como medio de comunicación $\mathrm{v}$ las aportaciones aue realiza como medio de comunicación, 
En segundo lugar, orientar al anunciante con este nuevo campo de conocimiento mediante una descripción de su situación en España y una definición y conceptualización de esta disciplina. La identificación de las características y ventajas del uso del teléfono móvil como medio en las estrategias de marketing y publicidad y las distintas modalidades de estrategias que se pueden llevar a cabo y concretando mediante ejemplos sus usos dentro de la estrategia general de marketing.

Por lo tanto, la intención de este texto es recoger la incidencia positiva del teléfono móvil sobre el marketing y la publicidad. Aunque se han dado pequeñas pinceladas, no se ha querido entrar en referencias críticas y tal vez más pesimistas sobre si el teléfono móvil es la culminación de la modernidad o no. Autores de referencia plasman estas otras consecuencias de la aparición de este medio, tan "filosóficamente interesante".

Algunas más contrarias, como la de Ferraris (Ferraris, 2008), que cuestiona el teléfono móvil como instrumento de construcción de la realidad social, y ya que "está por todas partes, nos une con un hilo invisible - puesto que no tiene hilos- y al mismo tiempo, a diferencia del teléfono fijo, desplaza la presencia". Autor que planea como tesis fundamental de su obra que: la ontología social se apoya en un sistema de escritura que puede prescindir del móvil (...) pero del que el móvil constituye el emblema absoluto, puesto que permite o promete la conexión a todos los sistemas de comunicación oral y escrita, el acceso a todos los circuitos de registro (escritura, imágenes, música), verificar el propio extracto de cuenta, pagar el billete de metro o la entrada a la ópera y, si se quisiera, descargar este libro y leerlo en el tren. Este autor otorga al móvil la categoría de máquina de escribir y para escribir, por ser un soporte sobre el que se escribe y que almacena todo aquello escrito.

Otras más tremendistas, como la de Virilio (Virilio, 1999) que acusa a las pantallas, y no sólo a la del móvil, también la de la televisión y el ordenador, de matar el espacio, el mundo finito, de estar construyendo un mundo en el que no hay tiempos, no hay geografía, un mundo sin horizonte terrestre en el que el océano es la escalera principal. Un mundo en el que lo digital está sustituyendo a lo analógico, lo real. Incluso en el tercer entorno que cita Echeverria (Echeverria, 1999), esa ciudad global, electrónica y digital fruto del impacto de las tecnologías de la información y la telecomunicación en la sociedad, podría ubicarse este marketing móvil que se trata en este texto. Pero, como se ha comentado antes, no será el objeto de estudio en esta ocasión, comentar estas consecuencias.

\section{REFERENCIAS}

American Marketing Association. (2008). The American Marketing Association Releases New Definition for Marketing. Recuperado el 2 de agosto de 2009, de http:/ / www.marketingpower.com/AboutAMA/ 
Documents / American\%20Marketing\%20Association\%20Releases\%20New\%20Defini tion \%20for \%20Marketing.pdf.

ANEI. (2007). Marketing, internet y Empresas. Recuperado el 20 de abril de 2010, de http://www.a-nei.org/formacion/.

Berlo, David K. (2004). El proceso de la comunicación: Introducción a la teoría y a la práctica. ( $3^{\mathrm{a}}$ ed.). Buenos Aires: El Ateneo.

Dickinger, A., Haghirian, P., Murphy, J. \& Scharl, A. (2004). An Investigation and conceptual model of sms marketing. Paper presented at the $37^{\text {th }}$ Hawaii International Conference on System Sciences (HICSS-37) IEEE Press. Hawaii.

Echeverría, J. (1999). Los Señores del aire: Telépolis y el Tercer Entorno. Barcelona: Destino.

Eco, H. (2005). El teléfono móvil y la verdad. L'Espresso.

Escuderos, V. (2006). Una realidad que llama a nuestra puerta. Marketing móvil de permiso incentivado. Control, 527.

Fernández Vicente, A. (2006). Prospectiva sobre la telefonía móvil y la digitalización de los sentidos: riesgos de un entorno integral calculable. Paper presented at the III Congreso On- line Observatorio para la Cibersociedad. Recuperado el 4 de marzo de 2008 de, http://www.cibersociedad.net/congres2006/gts/comunicacio.php?\&id=126.

Ferraris, M. (2008). ¿Dónde estás? Ontología del teléfono móvil. (Traducción de Carmen Revilla). Barcelona: Marbot Ediciones.

González, C. (2005). Principios básicos de comunicación. (9ª ed). México: Trillas.

Haig, M. (2002). Mobile marketing. The message revolution. Londres: Kogan Page.

Hermoso De Mendoza Blanco, C. (2004). Móviles, nuevas formas de comunicación. Revista IpMark, 616: 30-34.

Kotler, P. \& Armstrong, G. (2006). Marketing. (10 ed.). Madrid: Pearson Education.

Lucas Martín, A., García Galera, C. \& Ruiz San Román, J. A. (1999). Sociología de la comunicación. Madrid: Trotta.

Martín De Bernardo Gonzáleza, C. \& Priede Bergamini, T. (2007): Marketing móvil. Una nueva herramienta de comunicación. Análisis y nuevas perspectivas para el mercado español. 
Mcluhan, M. (1973): La comprensión de los medios como extensión del hombre. México: Diana.

Michael, A. \& Salter, B. (2006). Mobile Marketing. Achieving ompetitive advantages through wireless technology. Londres: Elsevier.

Mobile Marketing Association (2008): Mobile Marketing Industry Glossary.

Version 2008. Recuperado el 2 de Julio de 2009, de

http://mmaglobal.com/uploads/glossary.pdf.

Román, F., González-Mesones, F. \& Marinas, I. (2005). Mobile MK. La revolución multimedia. Madrid: Editorial ESIC.

Sánchez Guzmán, J. R. (2005). Lo fundamental del marketing. Madrid: Grupo Konecta.

Virilio, P. (1999). La bomba informática. Madrid: Cátedra.

\section{Laura Melendo Rodríguez-Carmona}

Doctora en Ciencias de la Información, es profesora de la Facultad de Ciencias de la Comunicación en la Universidad Camilo José Cela. Su área de conocimiento se centra en el proceso de planificación y medios de comunicación publicitarios. Además de su labor docente, realiza la coordinación de las nuevas tecnologías aplicadas a la docencia en dicha facultad. Realiza colaboraciones con EAE Madrid y con el Colegio Oficial de Sociólogos y Politólogos de Madrid. 